\title{
Risk factor and perinatal outcome of preterm delivery in a tertiary care centre in rural Haryana
}

\author{
Sunaina Singla, Banashree Das*
}

\begin{abstract}
Department of Obstetrics and Gynecology, Shree Guru Gobind Singh Tricentenary Medical College Hospital and Research Institute, Budhera, Gurgaon, Haryana, India
\end{abstract}

Received: 30 July 2020

Revised: 06 September 2020

Accepted: 08 September 2020

\author{
*Correspondence: \\ Dr. Banashree Das, \\ E-mail: banashree_a@yahoo.com
}

Copyright: (C) the author(s), publisher and licensee Medip Academy. This is an open-access article distributed under the terms of the Creative Commons Attribution Non-Commercial License, which permits unrestricted non-commercial use, distribution, and reproduction in any medium, provided the original work is properly cited.

\section{ABSTRACT}

Background: Aim of the study was to identify risk factors and to assess neonatal mortality and morbidity associated with preterm delivery in patient attending a tertiary care centre in rural Haryana.

Methods: This retrospective cohort study was conducted in Shree Guru Gobind Singh Tricentenary Medical College, over a period of one year (January to December). All pre-term deliveries were included in the study. They were followed up from admission till delivery and till discharge from hospital. Various, parameters like maternal age, associated medical disorder, obstetric complications, gestational age, neonatal mortality, need of neonatal intensive care and condition of baby at discharge were analyzed.

Results: In the present study, incidence of preterm deliveries was $16.1 \%$. The most common risk factor found to be history of previous abortion $(23.6 \%)$, preterm premature rupture of membrane (17.1\%), Intra-uterine growth restriction (IUGR) with oligohydramnios $(10.5 \%)$, hypertensive disorder during pregnancy $(5.9 \%)$, and antepartum hemorrhage (4.6\%). But majority of the patient $(56.5 \%)$ no cause could be identify. Out of total 160 preterm births 3 were still born and 157 live preterm births, and out of which total Neonatal intensive care (NICU) admission were 60. Mortality rate was $100 \%$ in neonate weighing less than $1000 \mathrm{gm}$ and $18 \%$ in babies weighing less than $2000 \mathrm{gm}$.

Conclusions: The commonest risk factor for preterm delivery is previous history of abortion and adverse perinatal outcome is inversely proportionate to the period of gestation at the time of delivery. All efforts should be made to prolong the pregnancy beyond 34 weeks by identifying and actively managing the risk factors for better neonatal outcome.

Keywords: Preterm delivery, Risk factors, Previous abortion, Preterm birth, Perinatal outcome

\section{INTRODUCTION}

Preterm labour (PTL) is defined as the onset of the labour before the 37 th completed weeks of gestation which is calculated from the first day of her last menstrual period or early trimester ultrasonography. It complicates about $10 \%$ to $15 \%$ of all pregnancies and is the most common cause of perinatal morbidity and mortality. Preterm delivery affects 1 in 10 births (11\%) in U.S.A and even greater births in developing countries and causes $40 \%$ to $75 \%$ neonatal deaths. ${ }^{1}$ Over $60 \%$ of preterm births occurred in
Sub-saharan Africa and South Asia as compared to other parts of the world. ${ }^{2}$ India is one of the ten countries with the highest numbers of estimated preterm birth. ${ }^{3}$ The causes of pre-term birth could be maternal, fetal, placental and others. Both maternal and fetal factors are more frequently seen in pregnancies occurring after assisted fertility treatments, thus increasing the risk of both spontaneous and provider-initiated preterm births., ${ }^{4,5}$ Nearly three-fourth of perinatal deaths occur in fetus that are delivered at $<37$ weeks, and about $40 \%$ of these mortality occurs in those delivered at less than 32 weeks. 
Moreover, pre-term birth has lifelong effects on neurodevelopmental functioning such as cerebral palsy, mental retardation, visual disorders like retinopathy of prematurity and increased risk of chronic disease in adulthood. ${ }^{6}$ Preterm birth often need for Neonatal intensive care unit (NICU). The economic cost of preterm birth is high due to neonatal intensive care and longer stay in hospital, sometimes for months. ${ }^{2}$

Hence, there is need to predict risk factors associated with preterm birth to plan for antenatal care to prevent preterm birth and to improve perinatal outcome.

\section{METHODS}

This retrospective cohort study was conducted in department of obstetrics and Gynecology, Shree Guru Gobind Singh Tricentenary Medical College Hospital and Research Institute, Budhera, Haryana. Case records of all pre-term deliveries during a period of one year (January to December) were taken from the medical records department and analyzed. All preterm deliveries admitted to the labour room, spontaneous or induced were included in the study. All patients who delivered before 28 completed weeks and in that where exact period of gestation could not be ascertained were excluded from the study. Risk factors found were categorized: antepartum hemorrhage, medical disorders, hypothyroidism, Premature rupture of membranes (PROM), multiple pregnancy, oligohydramnios / polyhydramnios, hypertensives disorders. They were followed up from admission till delivery and discharge from hospital. Various parameters were analyzed like maternal age, associated medical disorders, obstetric complications, gestational age at delivery, need of NICU, neonatal mortality and condition of baby at discharge. Statistical analysis was done using Statistical package for the social sciences (SPSS)- 20 version software.

\section{RESULTS}

During this study period, total deliveries were 944, of which full-term were 792 and Preterm deliveries were 152 $(16.1 \%)$. Induced preterm were $21(13.8 \%)$ and spontaneous preterm deliveries were 131 (86.2\%).

In present study, the relationship of preterm birth with maternal age was studied, maximum $65 \%$ preterm births occurred to the mother in age group of 20-25 years and only $0.6 \%$ in over 35 years of age (Figure 1 ).

Out of 152 preterm delivery $35.5 \%$ were primigravida and $30.20 \%$ were 2nd gravida as shown in Figure 2.

In present study, more than half $(78.9 \%)$ of the preterm deliveries were between 34-37 weeks of gestation and only $7.8 \%$ preterm deliveries were less than 32 weeks (Figure $3)$.

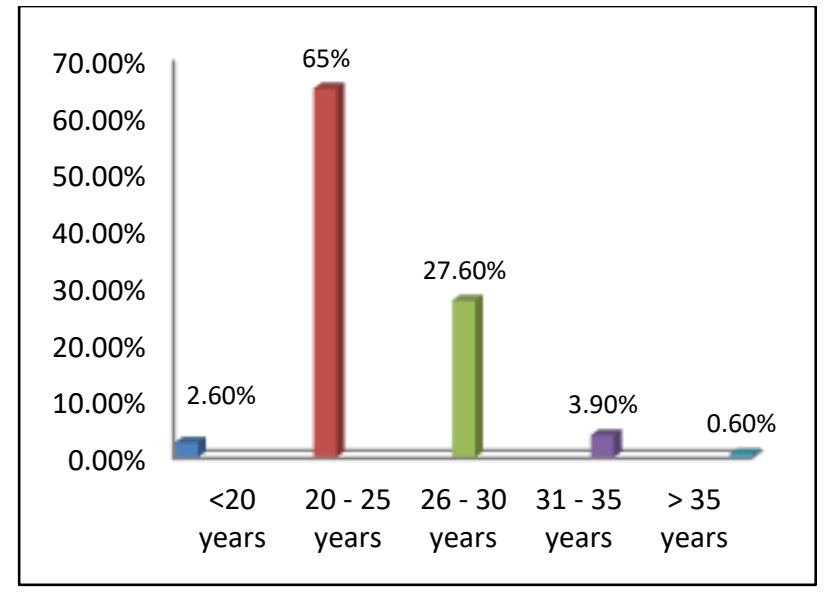

Figure 1: Age distribution in relation to preterm birth.

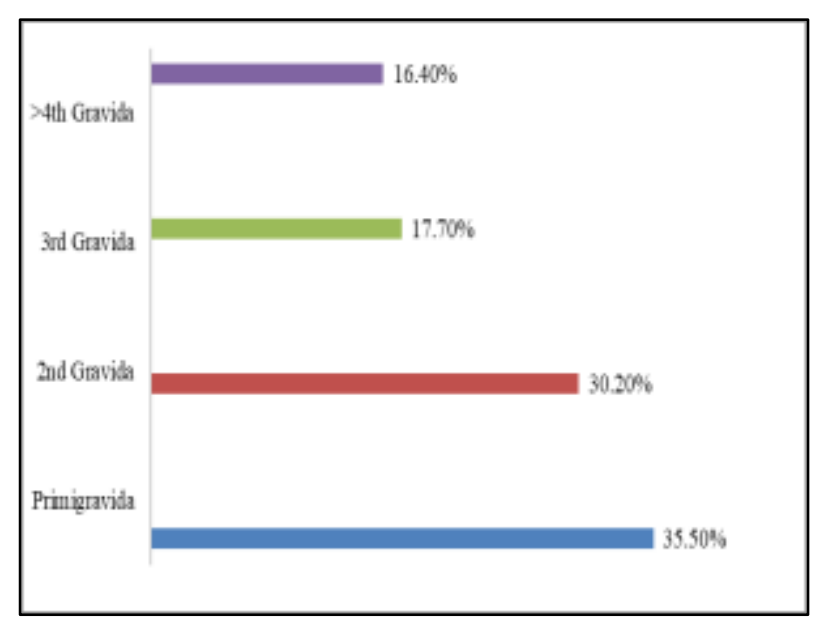

Figure 2: Distribution of preterm birth according to parity.

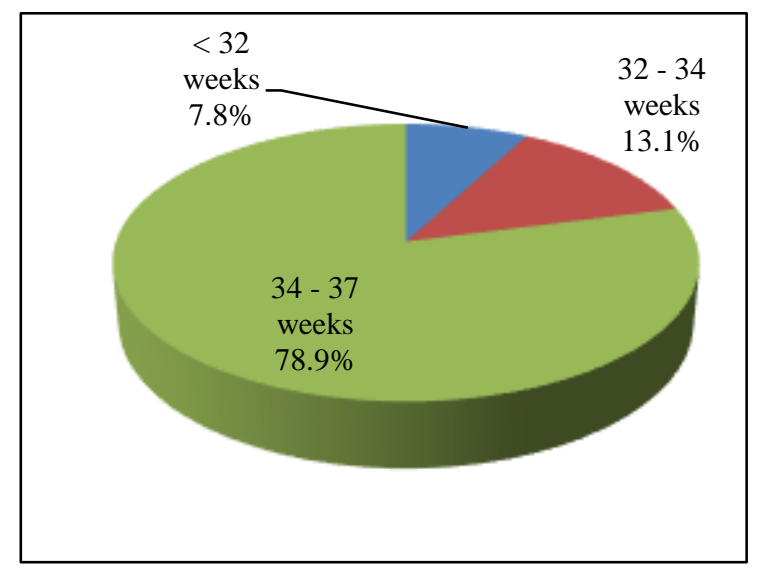

Figure 3: Gestational age at the time of delivery.

In present study, total $23.6 \%$ had history of previous abortion followed by $14.4 \%$ preterm birth was associated with a history of one previous abortion and only $2.60 \%$ had history of more than 2 abortions (Figure 4). 


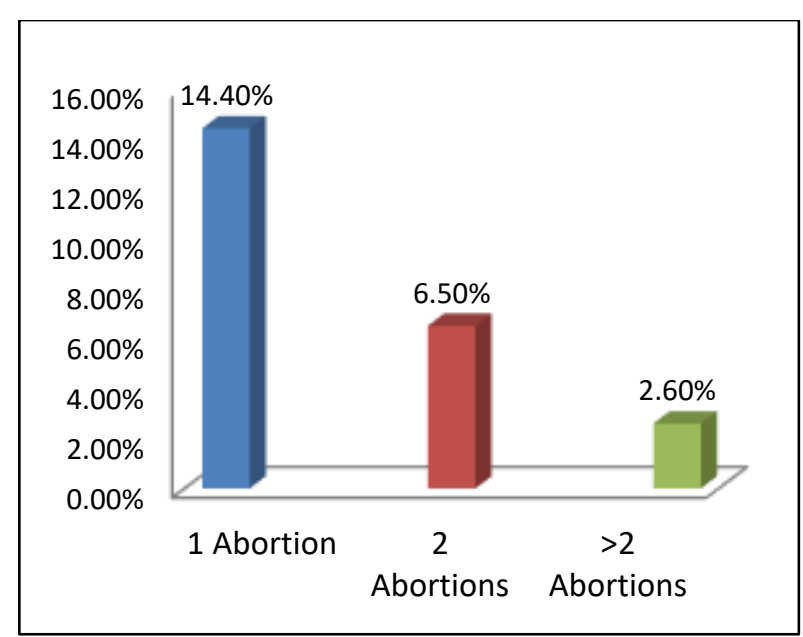

Figure 4: Number of abortions in relation to preterm birth.

Table 1: Shows risk factors of preterm birth.

\begin{tabular}{|lll|}
\hline Risk factors & $\begin{array}{l}\text { No. of cases } \\
(\mathbf{n = 1 5 2})\end{array}$ & Percentage \\
\hline Previous abortion & 36 & 23.6 \\
\hline $\begin{array}{l}\text { Preterm rupture of } \\
\text { membranes }\end{array}$ & 26 & 17.5 \\
\hline $\begin{array}{l}\text { Severe } \\
\text { oligohydroamnios with } \\
\text { IUGR }\end{array}$ & 16 & 10.5 \\
\hline Hypertension & 9 & \\
\hline $\begin{array}{l}\text { Antepartum } \\
\text { hemorrhage }\end{array}$ & 7 & 5.9 \\
\hline Mutifetal pregnancy & 7 & 4.6 \\
\hline Hypothyroidism & 6 & 4.6 \\
\hline Vaginal infections & 2 & 3.9 \\
\hline Idiopathic & 77 & 1.3 \\
\hline
\end{tabular}

Table 1 shows the various risk factors for preterm delivery. Previous history of abortion (23.6\%), was found to be the most common cause of preterm labour followed by preterm premature rupture of membranes $(17.5 \%)$ and severe oligohydramnios with IUGR $(10.5 \%)$. Others risk factors which were associated with preterm labour were hypertensive disorders during pregnancy $5.9 \%$. But in $50.6 \%$ no risk factor could be identified.

\section{Neonatal outcome}

In present study, out of 152 preterm deliveries (160 neonates), 157 were preterm live births and 3 were still born. Out of which, 60 neonates required NICU admission. 7 neonates died during NICU stay (Flow chart 1).

In present study, $38 \%$ neonates required NICU admission. In present study, out of 60 neonates 23 neonates were admitted to the NICU for less than 24 hours and 11 neonates needed to stay in NICU for 1 to 3 weeks (Figure $5)$.

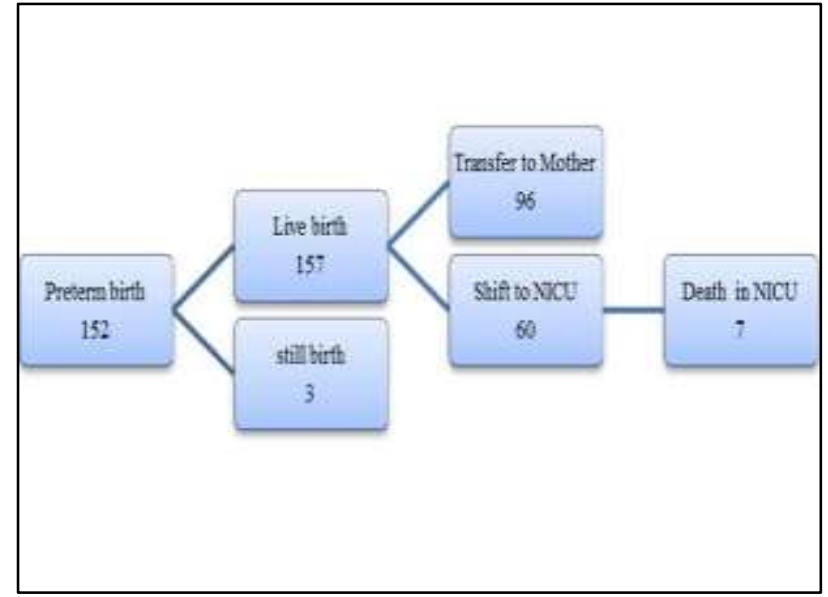

Flow chart 1: Pre-term deliveries.

In present study, $38 \%$ of the neonates were admitted to the NICU either for observation for prematurity and various other complications. The most common complications noted in preterm neonates were jaundice (38) followed by respiratory distress syndrome which was seen in 14 cases and asphyxia in 10 cases (table 2)

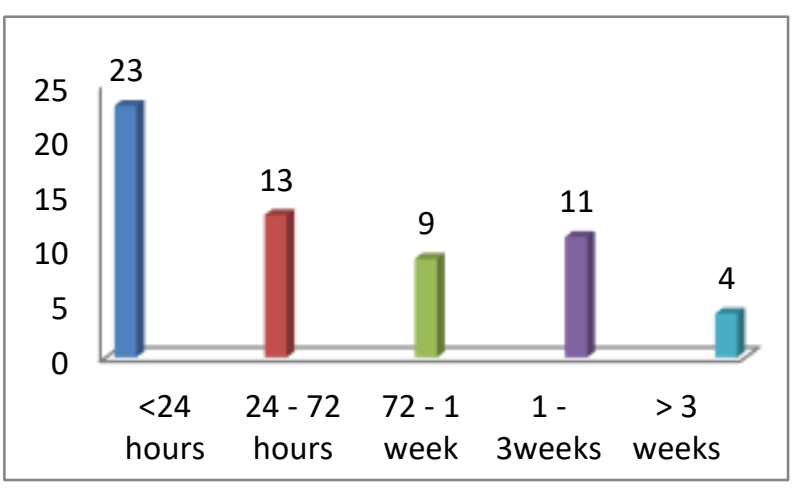

Figure 5: Duration of NICU stay.

In present study birth weight had significant association with neonatal mortality. All the neonates weighing more than 2000 gm survived (Table 3). Mortality rate was $100 \%$ in neonates weighing less than $1000 \mathrm{gm}$. In the present study it was observed that all seven neonate who died in NICU were born before 34 weeks of gestation (Table 4).

Table 2: Indication of NICU admission.

\begin{tabular}{|lll|}
\hline $\begin{array}{l}\text { Neonatal outcome } \\
(\mathbf{n = 6 0})\end{array}$ & Number & Percentage \\
\hline $\begin{array}{l}\text { Respiratory distress } \\
\text { syndrome }\end{array}$ & 14 & 23.33 \\
\hline Asphyxia & 10 & 16.66 \\
\hline Jaundice & 38 & 63.33 \\
\hline Septicaemia & 6 & 20 \\
\hline Hypothermia & 5 & 8.33 \\
\hline Hypoglycaemia & 7 & 11.6 \\
\hline Congenital anomaly & 1 & 1.6 \\
\hline
\end{tabular}


Table 3: Association between birth weight and neonatal mortality.

\begin{tabular}{|l|l|l|}
\hline Weight (grams) & Number & $\begin{array}{l}\text { Mortality } \\
(\%)\end{array}$ \\
\hline$<\mathbf{1 0 0 0}$ & 3 & $3(100)$ \\
\hline $\mathbf{1 0 0 0 - 1 4 9 9}$ & 11 & $1(9.09)$ \\
\hline $\mathbf{1 5 0 0 - 2 0 0 0}$ & 37 & $3(8.1)$ \\
\hline$>\mathbf{2 0 0 0}$ & 105 & Nil \\
\hline
\end{tabular}

Table 4: Relation of gestational age with perinatal mortality.

\begin{tabular}{|lll|}
\hline Gestational Age & $\begin{array}{l}\text { Preterm birth } \\
(\%)\end{array}$ & $\begin{array}{l}\text { Mortality } \\
(\%)\end{array}$ \\
\hline <32 weeks & 7.8 & 50 \\
\hline 32-34 weeks & 13.1 & 5 \\
\hline 34 - 37 weeks & 78.9 & Nil \\
\hline
\end{tabular}

\section{DISCUSSION}

Incidence of preterm delivery observed in present study was similar to the report published from other parts of the country and abroad.

Preterm births are influenced by many factors, from the maternal risk factors, placental related infections, pregnancy related complications and the others idiopathic factors.

It has been observed that extremes of maternal age play important role in preterm birth. Shetty et al reported incidence of preterm births at less than 25 years $(37 \%)$ and more than 35 years $(5.5 \%) .{ }^{9}$ But in the present study $67.6 \%$ of the patients at less than 25 years and only $0.6 \%$ above 35 years.

In our study we observed that primigravida have higher chances $(35.5 \%)$ of preterm delivery than second gravida $(30.2 \%)$. Arogya et al shows that multiparous women have higher chances at preterm delivery $(72.9 \%)$ than primigravida $(27.08 \%){ }^{12}$

Etiology of preterm labor is multifactorial. In present study, as high as $23.6 \%$ patients had previous history of abortion. $14.4 \%$ had history of only one abortion. Hence, previously history of abortion is also a risk factor for preterm births which correlates with EPIPAGE study. ${ }^{13}$

The second common maternal obstetrical risk factor in our study was preterm premature rupture of membranes $17.5 \%$ which was similar to $(18.1 \%)$ study reported by Shetty et al. ${ }^{9}$

Singh Uma et al found that approximately $10.8 \%$ of preterm births are associated with antepartum hemorrhage. Contrary to that in present study antepartum hemorrhage was associated with only $4.6 \%$.
We observed that neonatal hyperbilirubinemia (63.33\%) and RDS (23.33\%) were the most common causes of morbidity in preterm neonates. Sehgal et al reported that neonatal hyperbilirubinemia $(78 \%)$ and Respiratory distress syndrome (RDS) (65\%) were the most common causes of morbidity in extremely low birth weight babies. ${ }^{14}$

Table 5: Comparison of Incidence of Preterm birth.

\begin{tabular}{|c|c|}
\hline Country & $\begin{array}{l}\text { Preterm birth } \\
(\%)\end{array}$ \\
\hline 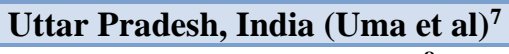 & 20.9 \\
\hline Zimbabwe (Shingairai et al) $^{8}$ & 16.4 \\
\hline Karnataka, India (Shetty et al) ${ }^{9}$ & 18.01 \\
\hline Australia (Robert et al) ${ }^{10}$ & 5.5 \\
\hline U.S.A (Martin et al) ${ }^{11}$ & 12.3 \\
\hline Present study & 16.1 \\
\hline
\end{tabular}

In present study, maximum neonatal mortality (55\%) was seen in those neonates who were born before 34 weeks of gestation. Similarly, Uma et al reported $30.4 \%$ neonatal mortality in neonates born before 34 weeks gestational age while it was only $3.4 \%$ in those born after 34 weeks gestational age. ${ }^{7}$ This clearly indicates that benefit of prolonging pregnancy beyond 34 weeks in cases of preterm labour.

\section{CONCLUSION}

Incidence of preterm delivery in the present study was similar to studies reported from different part of country. In present study, previous history of abortion is a major risk factor besides history of preterm premature rupture of membranes and severe oligohydramnios with IUGR. Antepartum haemorrhage, hypertensive disorders during pregnancy were found to be significantly less in our study as compared to other reported studies. Adverse perinatal outcome is inversely proportionate to the period of gestation at the time of delivery. All efforts should be made to prolong the pregnancy beyond 34 weeks by identifying and actively managing the risk factors for better neonatal outcome.

Funding: No funding sources

Conflict of interest: None declared

Ethical approval: The study was approved by the Institutional Ethics Committee

\section{REFERENCES}

1. McPheeters ML, Miller WC, Hartmann KE, Savitz DA, Kaufman JS, Garrett JM, et al. The epidemiology of threatened preterm labor: a prospective cohort study. Am J Obstet Gynecol. 2005;192;1325-9.

2. Born too soon. The Global Action Report for Preterm Birth, MoD, PMNCH, Save the children, WHO, New York, NY, USA. 2012.

3. Blencowe H, Cousens S, Oestergaard M, Chou D, Møller AB, Narwal R et al. National, regional and 
worldwide estimates of preterm birth. Lancet. 2012;379(9832):2162-72.

4. Mukhopadhyaya N, Arunkumaran S. Reproductive outcomes after in-vitro fertilisation. Curr Opin Obstet Gynecol. 2007;19:113-9.

5. Kalra SK, Molinaro TA. The association of in vitriol fertilization and perinatal morbidity. Semin Reprod Med. 2008;26:423-35.

6. Shrestha S, Dangol SS, Shrestha M, Shrestha RP. Outcome of preterm babies and associated risk factors in a hospital. J Nepal Med Assoc. 2010;50(180).

7. Singh Uma, Singh N, Seth S. A prospective analysis of etiology and outcome of preterm labor. J Obstet Gynecol India. 2007;57(1):48-52.

8. Shingairai AF, Siobon DH, Godfrey BW. Risk factors for prematurity at Harare Maternity Hospital, Zimbabwe. Int J Epidemiology. 2004;33:1194-201.

9. Shetty MB, Krupa BM, Mounica Malayalam,Asha Swarup, Davis Sabu Pathadan, Suneha Pocha. Preterm birth:associated risk factors and outcome in tertiary care center. Int J Reprod Contracept Obstet Gynecol. 2017;6(8):3271-4.

10. Robert CL, Algert CS, Raines GC, Peat B, Henderson-Smart DJ. Delivery of singleton preterm infants in New South Wales 1990-1997. Aust NZJ Obstet Gynecol. 2003;43:32-7.

11. Martin JA, Kocharekar KD, Strobino DM, Guyer B, MacDorman MF. Annual summary of Vital statistics2003.Pediatrics. 2005;115:619-34.

12. Prakash SA, Rasquinha S, Rajaratnam A. Analysis of Risk factors and outcome of Preterm Labour.Int J Eng Sci. 2016;6(8):2602-4.

13. Moreau C, Kaminiski M, Angel PY, Bouyer J, Escande B, Thiriez $\mathrm{G}$ et al. Previous induced abortions and the risk of very preterm delivery- results of EPIPAGE study. BJOG. 2005;112:430-7.

14. Sehgal A, Telang S, Paseah SM et al. Maternal profile and immediate outcome in extremely low birth weight babies. Delhi Trop Doct 2004;25(1):43-7.

Cite this article as: Singla S, Das B. Risk factor and perinatal outcome of preterm delivery in a tertiary care centre in rural Haryana. Int J Reprod Contracept Obstet Gynecol 2020;9:4187-91. 